\title{
0 Modelo de Relações Salariais: Uma análise de Empresas Automobilísticas no Brasil
}

\section{The Salaries Relations Model: an Analysis of Automotive Firms in Brazil}

Rejane Prevot Nascimento ${ }^{1}$

Lidia Micaela Segre ${ }^{2}$

\section{Resumo}

Face ao contexto de crise do modelo de acumulação capitalista na década de 1970, as empresas automobilisticas, em todo o mundo, têm adotado novos modelos produtivos. A compreensão do processo de concepção e incorporação desses modelos é fundamental posto que, ainda hoje, o setor automobilistico representa uma fonte de inovações organizacionais para outros setores industriais e de serviços. Nesse sentido, este artigo tem como objetivo analisar as relações salariais em empresas automobilisticas brasileiras, a partir da estrutura de análise proposta por Durand (1998), a qual está baseada em quatro elementos: organização do trabalho, sistema de remuneração, atuação dos sindicatos e relações hierárquicas. A utilização dessa estrutura de análise permite a identificação dos conflitos inerentes a cada planta e o grau de coerência dos elementos, necessário para a obtenção de melhores resultados globais na indústria. $A$ análise dos estudos de caso à luz do modelo apresentado indica que, no atual contexto de acumulação capitalista, não existe coerência entre os elementos da relação salarial tal como se obtinha na organização 'fordista'.

Palavras -chave: setor automobilístico brasileiro, relações salariais, relações de trabalho

\begin{abstract}
In the face of the context brought about by the accumulation of capital model upheld by the Ford-type industry paradigm in the 1970s, automotive companies all over the world have adopted new production models. An understanding of the process by which these models have been conceived and incorporated is essential in view of the fact that the automotive field continues to be a source of organizational innovations for other industrial and service fields. From this standpoint, this article aims to analyze salary relations in Brazilian automotive companies based on the four elements according to Durand's (1998) structure: work organization, remuneration systems, labor union actions and hierarchical relations. The use of this structure enables the researcher to identify conflicts inherent to each plant and the degree of coherence of the aforementioned elements needed to achieve the best overall results in the industry. The analysis of the case study, in the light of the model presented here, shows that in the context of capital accumulation, there is no coherence in the elements of salary relations similar to that which existed in Ford-type organizations.
\end{abstract}

Key Words: Brazilian automotive sector, salary relations, work relations.

\footnotetext{
'D.Sc. Engenharia de Produção, Instituto de pós-graduação e pesquisa em Administração da Universidade Federal do Rio de Janeiro - COPPEAD/UFRJ Professora do Mestrado em Administração/UNIGRANRIO. Endereço: Rua da Lapa, 86 / $9^{\circ}$ andar Centro - Rio de Janeiro/RJ - BRASIL - CEP 20021-180 . E-mail: rejaneprevot@uol.com.br

${ }^{2}$ D.Sc. Engenharia de Sistemas e Computação - Instituto de pós-graduação e pesquisa em Administração da Universidade Federal do Rio de Janeiro COPPEAD/UFRJ. Professora do Mestrado em Administração/UNIGRANRIO. Endereço: Rua da Lapa, 86 / $9^{\circ}$ andar . Centro - Rio de Janeiro/RJ - BRASIL - CEP 20021-180. E-mail: micaela@ms.microlink.com.br
}

Artigo submetido em setembro de 2007 e aceito em novembro de 2007 


\section{Introdução}

A crise do modelo de acumulação capitalista na década de 1970, que teve, como conseqüência direta, a crise do modelo 'fordista', despertou as empresas ocidentais para a necessidade da adoção de novos modelos produtivos e de organização do trabalho. Jean Pierre Durand, na introdução do livro "L'avenir du travail a la chaîne" (1998), identifica, na história da indústria automobilística mundial, a existência de três modelos "canônicos": o Modelo "Fordiano" (ou fordista), o Modelo Japonês e o Modelo Kalmariano, este originado da forma de organização de trabalho implantada em Kalmar, na Suécia, na década de 1970. Por "canônico" pode-se entender um sistema ideal, jamais encontrado na realidade, mas construído a partir de características essenciais que se combinam para dar uma coerência sistêmica a cada modelo organizacional. Tais modelos, por serem canônicos, servem como referências a serem copiadas pelas empresas para atender às suas necessidades de coerência interna para a eficácia do trabalho. Dentre os modelos descritos, pode-se afirmar que o trabalho em grupo do modelo japonês original, e suas adaptações, foram os mais adotados nas montadoras de todo o mundo, nos últimos trinta anos.

De acordo com o autor e com os resultados das pesquisas desenvolvidas por Carleial et al. (2002), cada modelo de organização do trabalho demanda por uma estrutura particular de relações salariais, compatível não só com as características da estrutura produtiva e da gestão da força de trabalho, específicas de cada montadora, mas também, com as características da região onde estão inseridas. Deve-se considerar que os transplantes do modelo japonês para empresas americanas e européias adaptaram-se às condições locais das montadoras, configurando hibridizações do modelo original, como assinala o autor:

De fato, a hibridização depende tanto das trajetórias históricas das montadoras como das estruturas sócio-profissionais da mão de obra, do estágio do movimento sindical, do sistema social e jurídico de proteção dos assalariados etc. O resultado, sempre provisório, é uma multiplicidade de situações que se originam de um mesmo princípio organizacional ou que mesmo apresentando-se semelhantes, possuem significados muito diferentes no que se refere aos impactos sobre os trabalhadores, sobre a autonomia do trabalho etc. (DURAND, 1998, p.12, traduzido pelas autoras)

Baseado nessas considerações, esse autor apresenta uma estrutura de análise das relações salariais constituída a partir de quatro elementos básicos, fortemente imbricados: a organização do trabalho, as relações hierárquicas, o sistema de remuneração e a atuação dos sindicatos. Para o autor, a obtenção de maior eficácia do trabalho pelas firmas e, conseqüentemente, de melhores resultados globais depende da coerência entre estes quatro elementos.

A estrutura de análise das relações salariais proposta por Durand é produto das pesquisas desenvolvidas no âmbito do Groupe d’Étude et de Recherche Permanent sur 1'Industrie et les Salariés de l'Automobile (GERPISA - Grupo de Estudos e de Pesquisa Permanente sobre a Indústria e os Assalariados Automobilísticos), baseado na Universidade de Evry. Esse grupo reúne pesquisadores de todo o mundo, voltados para a análise das transformações do capitalismo moderno, de seus impactos sobre a indústria automobilística, assim como para a análise dos novos modelos produtivos, implementados nesta indústria. O GERPISA caracteriza-se por apresentar uma perspectiva teórico-conceitual distinta e alternativa àquela proposta pelos pesquisadores do Massachussets Institute of Technology (MIT) e difundida em Womack, Jones \& Roos (1992), em que se defende a predominância da produção enxuta (lean production) como modelo único no setor.

Diante de tais pontos de vista, este artigo tem como objetivo apresentar um estudo de quatro plantas automobilísticas no Brasil, segundo a estrutura de análise das relações salariais proposta por Durand. O estudo abrange plantas das montadoras: Mercedes Benz (São Bernardo/SP e Juiz de Fora/MG) e Volkswagen (São Bernardo/SP e Resende/RJ). A metodologia utilizada para desenvolvimento do artigo consiste em uma pesquisa bibliográfica, além do estudo de casos, por meio de pesquisa de campo realizada nas plantas, com utilização de entrevistas semi-dirigidas com todos os níveis hierárquicos, observação participante e levantamento documental sobre as empresas investigadas. Foram realizadas, também, entrevistas com dirigentes dos sindicatos relacionados com as empresas pesquisadas. 
É interessante observar que a escolha das empresas teve como objetivo possibilitar uma comparação entre as estratégias empreendidas pelas montadoras nas regiões consideradas como brownfields, regiões com movimento sindical mais forte e consolidado, em geral com níveis de salários mais altos, e nas consideradas como greenfields, denominadas, assim, por apresentarem pouca densidade industrial e um movimento sindical menos estruturado, ou enfraquecido pelo desemprego local. Dessa forma, duas das empresas analisadas situamse no município de São Bernardo, na região do $\mathrm{ABC}$ paulista, considerada um brownfield. Das duas outras empresas, inauguradas na década de 90 - período em que ocorreu a terceira migração da indústria automobilística para o Brasil - uma situa-se em Juiz de Fora, e outra, em Resende. Ambas as cidades podem ser classificadas como greenfields.

A metodologia utilizada neste trabalho engloba pesquisa bibliográfica, observação participante e pesquisa de campo em quatro plantas de duas empresas automotivas - essa última consistindo da realização de entrevistas com dirigentes das empresas e dos respectivos sindicatos, gerentes e operadores.

O artigo se divide em três seções, além desta introdução. Na segunda seção é apresentada uma discussão teórica sobre a estrutura de análise das relações salariais; na terceira, descrevem-se e interpretam-se os estudos de caso com base na estrutura de análise apresentada, e a quarta e última seção contém as considerações finais do estudo.

\section{As Relações Salariais}

Segundo Durand (1998), a análise das relações salariais se faz necessária na medida em que a utilização das técnicas japonesas no ocidente fez com que surgissem novos modelos de relação salarial, que vêm substituir a estrutura de relações salariais estabelecida pelo 'fordismo'. Esses modelos surgem em contextos macroeconômicos e micro-sociais distintos, apresentando, portanto, características e resultados também diferentes. Entende-se aqui, como fatores macroeconômicos, o mercado de produtos e o mercado de trabalho e como fatores micro-sociais, a organização do trabalho (divisão do trabalho, relações hierárquicas), a evolução dos produtos/inovações, os processos técnicos e organizacionais da produção.

Os resultados da utilização das técnicas japonesas fora do Japão são distintos, em cada caso, porque a transposição destas técnicas, assim como sua hibridização, depende das histórias, das trajetórias e do contexto no qual estão inseridos os construtores. Portanto, para a compreensão da estrutura de relações salariais estabelecida por montadora é fundamental considerar, por exemplo, variáveis tais como condições de formação da mão-de-obra, situação dos sindicatos locais, arcabouço jurídico e social de relações de trabalho e de salários. Nesse sentido, podemos compreender a relação salarial como o resultado da interação desses fatores econômicos e sociais e a convergência desses com as estratégias empresariais.

Segundo Durand (1998), a relação salarial é estruturada a partir da imbricação de quatro variáveis microsociais, que serão explicitadas nos quatro parágrafos seguintes:

1. a organização do trabalho;

2. as relações hierárquicas;

3. o sistema de remuneração; e

4. a atuação dos sindicatos.

A organização do trabalho é a variável que se refere à relação entre os diferentes tipos de funcionários nas funções de alimentação, manutenção e preparação da produção, assim como à relação entre os trabalhadores, e, também, desses com os equipamentos colocados à sua disposição para exercer suas atividades. A organização do trabalho, conforme o autor, é o elemento que destaca os aspectos relativos à qualificação, à autonomia e à formação dos grupos de trabalho, entre outros.

A segunda variável diz respeito às relações hierárquicas que se estabelecem no interior da empresa e, às funções de execução, destacando a tarefa de gestão do trabalho. De fato, a constituição dos grupos de trabalho 
gerou ampliação das responsabilidades individuais no grupo e diminuição dos níveis hierárquicos nas empresas, na medida em que algumas atividades de controle, manutenção e verificação foram transferidas para os funcionários do nível operacional.

A terceira variável é o sistema de remuneração, que, segundo o autor, inclui as políticas salariais e as possibilidades de promoção, os benefícios e as formas alternativas de composição salarial (participação nos lucros e resultados, bônus etc), as regras de aumento de salários, internas da empresa e as que estão em vigência, estabelecidas oficialmente pelo governo. Nesse sentido, esses aspectos devem ser entendidos no contexto geral do país, do nível de desemprego e dos níveis salariais em vigor na sociedade.

Por último, a quarta variável, ou seja, a atuação dos sindicatos abrange as formas de ação sindical frente ao processo de reestruturação e reorganização do trabalho, à política salarial das empresas e às regras de aumento dos salários, assim como abrange a reação dos sindicatos ao processo de enxugamento de pessoal verificado nas empresas nos últimos anos, (DURAND, 1998; CARLEIAL et al., 2002)

Vale ressaltar que a preocupação dos pesquisadores do GERPISA na utilização da análise das relações salariais consiste em identificar se existe de fato um novo modelo de relações salariais, distinto do modelo 'fordista' no setor automobilístico; ou se existem vários modelos, e se esses são uma mera continuação do paradigma 'fordista' clássico.

Durand, Stewart \& Castillo (1998) levantam a hipótese de que a noção de modelo pode conduzir a uma perspectiva estática. A tentativa de analisar as relações salariais a partir de quatro variáveis possibilita uma subversão dessa visão estática, enxergando-as como um sistema dinâmico e variável. O problema identificado pelos autores na idéia de modelo é que ela não considera os conflitos inerentes aos processos produtivos, que também são responsáveis pelas transformações e inovações nesses processos: “(...) a análise das relações salariais no setor considerado nos fornece provas da natureza incerta das perspectivas salariais e de gestão, onde os conflitos e debates são os motores da inovação" (DURAND, STEWART \& CASTILLO, 1998, p. 390, traduzido pelas autoras).

A análise proposta por Durand tem como foco um aspecto da organização do trabalho que é o trabalho em grupo, em função do enorme número de empresas automotivas que o adotam e por essa técnica representar uma nova forma de racionalização do trabalho. Corroborando a importância adquirida pelo trabalho em grupo nos sistemas de produção modernos, devemos considerar que ele é largamente utilizado não apenas no setor automotivo, mas também em outros setores industriais e no setor de serviços.

A eficácia do trabalho em grupo está associada à existência de uma coerência entre os quatro elementos das relações salariais, anteriormente descritos, com o contexto de cada firma. Entretanto, a obtenção dessa coerência se torna difícil na medida em que os atores envolvidos possuem posições freqüentemente divergentes, gerando um confronto de lógicas de atuação completamente diferentes. Dessa forma, a existência de qualquer coerência, ou de algum ponto de equilíbrio entre essas lógicas, é transitória, dado o caráter altamente mutável dessas variáveis.

A questão proposta pelo autor e destacada por Carleial et al.(2002) é: como é possível construir uma relação salarial equilibrada e coerente, considerando-se as restrições impostas pelo contexto macroeconômico, o mercado de trabalho e o mercado de produtos? Para Durand (1998), o modelo 'fordista' de relação salarial apresentava uma coerência entre esses elementos posto que o mercado de trabalho oferecia, naquela época, ao setor automobilístico uma mão-de-obra pouco qualificada, adequada para o desempenho de tarefas monótonas e de caráter repetitivo, que não exigiam muito empenho intelectual ou formação do trabalhador, e uma coordenação das tarefas, estabelecida de forma hierárquica e bastante autoritária. Por outro lado, os produtos fabricados, de qualidade medíocre, atendiam às demandas de um mercado em expansão, pouco exigente e ávido pelo consumo. Para manter a produtividade, toda reivindicação salarial era imediatamente satisfeita pelo sistema. A relação salarial neste sistema tinha como função amenizar a existência do conflito capital $\mathrm{x}$ trabalho e, paralelamente, alavancar a demanda. 
Esse ciclo que garantia a manutenção do sistema, denominado por Durand de "virtuoso", vai rapidamente se converter em "vicioso" em fins da década de 1970, com a considerável perda de mercados pela indústria automobilística e a drástica redução dos efetivos. Ao mesmo tempo emergem como paradigmas bem sucedidos, os construtores japoneses, influenciando, com seu sistema produtivo, todo o setor automobilístico ocidental. É nesse contexto que se dá a transformação do modelo de relação salarial vigente no 'fordismo'.

Nesse sentido, podemos classificar os tipos de trabalho em grupo, implementados nas empresas fora do Japão, como hibridizações do modelo canônico Japonês, uma vez que são adotados, em condições de funcionamento, diversas daquelas encontradas no Japão, perdendo sua força "canônica" em relação ao paradigma japonês.

Por outro lado, podemos observar que as transformações desencadeadas pela importação dos conceitos da produção enxuta no Ocidente não se restringem apenas à organização do trabalho e do processo produtivo. A importação desses conceitos conduz necessariamente à definição de novas regras que mudam a configuração do trabalho: a emergência de novas demandas de qualificação, mais elevadas; a transformação das condições de trabalho, como, por exemplo, o uso de tentativas de arrefecimento dos ânimos sindicais; a mudança nos padrões de gestão dos recursos humanos, colocando em prática novos sistemas de avaliação dos empregados que propõem um cálculo do salário individualizado; o acirramento da competição entre os próprios trabalhadores (por meio da vigilância constante entre os membros da equipe, o controle sobre a qualidade do trabalho e mesmo com os próprios métodos de avaliação $360^{\circ}$, onde todos se avaliam). E, por fim, a introdução desses conceitos se dá, em muitos casos, em contextos de profunda instabilidade do emprego e de precariedade das condições de trabalho, como é o caso do Brasil.

Mais particularmente, no que tange ao processo de trabalho no chão de fábrica, o trabalho em grupo depende intrinsecamente do exercício da polivalência. De acordo com a polivalência e a rotação de postos de trabalho, impostas pelo trabalho em grupo, socializam o savoir faire dos empregados, já que o conhecimento é apropriado pelos outros operadores e pelos engenheiros. Esse conhecimento é utilizado para o cálculo dos tempos de execução e é incorporado à gama de atividades, ou seja, a socialização do saber operário leva, em última análise, a uma perda de autonomia sobre o trabalho. Por outro lado, no trabalho em grupo, os trabalhadores compartilham um conjunto limitado de tarefas, reproduzindo um padrão necessário para assegurar a qualidade e a regularidade da produção, que remete às características dos protocolos 'fordistas'.

Outro aspecto presente na adoção do trabalho em grupo é a possibilidade de a empresa obter um tipo de envolvimento do funcionário com o seu trabalho jamais conseguido pelos métodos de produção 'fordistas'. Tal envolvimento é obtido com a convergência dos quatro componentes do modelo de relações salariais.

Segundo Durand, o tipo de envolvimento utilizado pelo modelo japonês de gestão pode ser definido como 'meritocrático' (o "satei system"), pois recompensa os melhores funcionários por meio de maiores salários e promoções. Nas grandes empresas japonesas, esse sistema é alimentado por uma avaliação do desempenho do subordinado por seu superior hierárquico imediato. A avaliação abrange não somente os aspectos técnicos do trabalho, mas principalmente, os aspectos comportamentais, as atitudes e, mais particularmente, sua conformidade em atender aos objetivos propostos e às normas da empresa. Os resultados dessa avaliação determinam diretamente os aumentos de salário e o recebimento de premiações e bônus, e é também com base nela que são concedidas as promoções.

Quando esse modelo de avaliação foi transposto para o Ocidente, de acordo com o contexto macroeconômico, ele incorporou uma dimensão subjetiva de avaliação dos funcionários para a evolução dos salários. A diferença essencial é que a conformidade com a filosofia da empresa não representa mais somente um critério para o aumento dos salários; ela passa a representar, sobretudo, uma forma de conservação do emprego em um contexto de altos níveis de desemprego e expansão das formas de "subemprego" (trabalho informal, trabalho terceirizado e subcontratado etc.). Nesse sentido, o envolvimento no trabalho significa o engajamento dos assalariados com os objetivos de seu trabalho e da própria empresa, o que constitui uma norma comportamental, que deve ser seguida sob pena de demissão. No Ocidente, a permanente crise do emprego constitui um fator importante para o envolvimento dos operários. O envolvimento é "contratado" pela empresa, 
como define Durand, e significa, na prática, a aceitação implícita, pelo funcionário, de um contrato social: o indivíduo está submetido a uma ordem segundo a qual ele deve atender aos objetivos fixados socialmente, estar de acordo com as normas vigentes e executar o trabalho prescrito.

A gestão do trabalho por meio do "envolvimento contratado" tende a se difundir em razão da generalização da pressão do subemprego e do desemprego sobre os assalariados. Em algumas regiões há uma resistência dos sindicatos em relação a essa forma de avaliação, que nem sempre é clara; em outras firmas, nem mesmo a avaliação é necessária, pois os princípios 'fordistas' de imposição da disciplina continuam a imperar. Como foi apontado anteriormente, existe uma enorme diversidade de situações e modelos, de formas de envolvimento e das próprias formas de aplicação do trabalho em grupo, originando uma gama infinita de formas de conjunção dos elementos da relação salarial.

\section{Estudos de Caso}

Nesta seção apresentamos os estudos de caso nas plantas da Mercedes-Benz (São Bernardo e Juiz de Fora) e na Volkswagen (São Bernardo e Resende). Nosso interesse está centrado nas plantas que se reestruturam e naquelas que fazem parte dos investimentos mais recentes no setor automobilístico, por isso foram escolhidas as fábricas da Mercedes-Benz e da Volkswagen, instaladas em São Bernardo, uma vez que a partir do início da década de 1990, as plantas mencionadas passaram por um intenso processo de reestruturação técnica e organizacional.

A escolha das plantas da Volkswagen (Resende) e Mercedes-Benz (Juiz de Fora) deu-se por apresentarem, como característica, uma nova relocação industrial, configurando-se como verdadeiros greenfields, e permitindo às montadoras recompor novos padrões de organização do trabalho, da produção e de flexibilidade e novas estratégias de racionalidade de custos, entre outros.

As quatro fábricas estudadas apresentam como característica relevante a adoção do trabalho em grupo, como forma de conduzir mudanças organizacionais, pressionadas pela necessidade de se repensar mais profundamente as bases sobre as quais a produção e o trabalho se organizam.

A coleta de dados nas montadoras foi realizada a partir de várias visitas previamente programadas. Foram entrevistados diretores, gerentes e técnicos da área de produção, de recursos humanos (RH) e de planejamento estratégico, assim como os trabalhadores do 'chão-de-fábrica'. Também foram realizadas entrevistas com os representantes dos sindicatos do setor metalúrgico aos quais pertencem as empresas estudadas. Foi utilizado, ainda, o método de observação participante nas reuniões dos grupos de trabalho, nas plantas estudadas.

Schwartz \& Schwartz (1955 apud CICOUREL, 1990, p. 89) definem:

(...) observação participante como um processo pelo qual se mantém a presença do observador numa situação social com a finalidade de realizar uma investigação científica. O observador está em relação face a face com os observados e, ao participar da vida deles no seu cenário natural, colhe dados. Assim, o observador é parte do contexto sob observação, ao mesmo tempo modificando e sendo modificado por esse contexto.

Com a observação participante, o pesquisador pretende observar as pessoas de maneira tal, que a influência provocada pela sua presença seja a mínima possível.

\subsection{O Caso da Mercedes Benz de São Bernardo}

A Mercedes-Benz do Brasil (MBB) foi a empresa pioneira na produção de caminhões e ônibus no país. A primeira fábrica foi inaugurada em 1956, no Estado de São Paulo, em São Bernardo do Campo. Hoje, a empresa está concentrada na fabricação de caminhões, chassis de ônibus e motores. Atualmente emprega na ordem de 11 mil e 500 funcionários. Em 2000, a produção total da fábrica era de 38.267 mil unidades, e no ano de 2005 foi de 56.727 mil unidades, representando 55\% do total dessa gama de veículos no país (ANFAVEA, 2006). Vale destacar que, em 2000, o número de funcionários era de 10 mil. Desde 1994 vem implementando 
melhorias no processo produtivo, com a aplicação de novos métodos de trabalho e adoção de novas tecnologias.

É importante salientar que o objetivo para a implantação do processo de reestruturação foi agilizar processos e decisões, através de uma administração descentralizada; diminuição de níveis hierárquicos e a preparação de mão-de-obra para assumir novas responsabilidades e desafios. A fábrica organiza-se de forma integrada e enxuta. Para isso, a adoção de Just-in-Time, Kaizen, etc. tem papel preponderante, buscando o aperfeiçoamento do fluxo de produtos e a melhoria contínua, não só no interior do processo produtivo, mas em especial, com seus fornecedores de primeira linha.

A Mercedes-Benz de São Bernardo se caracteriza por um esforço de reestruturação menos centrada na adoção de inovações tecnológicas e mais, num processo planejado de inovações organizacionais. Essa reestruturação se deu de forma negociada, a partir de uma experiência inédita no país, que envolveu a empresa e o sindicato, por meio de sua Comissão de Fábrica, após uma greve na empresa em 1996. Foram efetuados acordos coletivos formais sobre a organização do sistema logístico, terceirização, células de manufatura, trabalho em grupo, programas de melhorais contínuas, plano de combate ao ruído, estrutura de cargos e salários, além de se negociarem temas como ergonomia e avaliação de desempenho (BRESCIANI, 1997).

Uma das mudanças organizacionais mais importantes foi a adoção do trabalho em grupo. Inicialmente foi implantado o Programa de Kaizen que treinou as pessoas para trabalhar em grupo. As principais melhorias obtidas, que favoreceram a implantação do trabalho em grupo, foram as seguintes: inúmeras operações de 'submontagem', que antigamente eram realizadas na própria linha de montagem, passaram a ser feitas em paralelo, ao lado da linha principal; o lay-out funcional das máquinas em linha foi substituído por lay-out em U para reduzir a movimentação das peças e favorecer o trabalho em grupo.

A intenção da empresa, segundo o Gerente de RH, foi motivar uma maior participação do empregado, que passou a ser polivalente. Ele é responsável pelo recebimento das peças, preparação das máquinas, operação e controle da qualidade, manutenção e, também, pela melhoria do desempenho da fábrica em relação à produtividade, à qualidade e aos custos.

O trabalho em grupo, em vigor na fábrica, segundo o coordenador dos trabalhos em grupo da empresa, foi baseado no modelo 'kalmariano' (adaptado para a cultura brasileira). Tanto os engenheiros da empresa, quanto os representantes do Sindicato foram à Suécia para conhecer o modelo na prática. Os grupos de trabalho têm autonomia em relação à divisão do trabalho, interrupção da produção, na rejeição de matéria-prima não conforme, na responsabilização pelas manutenções primárias e na operação polivalente das máquinas. Existem igualmente vários programas de formação técnica e comportamental que desenvolvem um alto grau de "polivalência" e facilitam a participação dos trabalhadores nas reuniões que regularmente realizam os grupos.

As reuniões entre os integrantes do grupo são realizadas semanalmente, no horário de trabalho, para discutir o gerenciamento, as melhorias e os problemas da equipe. Ocorrem ainda encontros mensais entre os porta-vozes e a gerência, e a cada dois meses são realizadas palestras para todos os funcionários sobre o andamento da empresa.

A partir de 1996, a Comissão de Fábrica (CF) conquistou o direito de receber informações prévias sobre mudanças organizacionais e tecnológicas na empresa. Assim são colocados, na discussão entre os diretivos da empresa e os representantes dos trabalhadores, temas como a elevação do ritmo de produção, o recurso às horas-extras, a prática da rotatividade, o controle do ritmo de linhas de montagens e outros. A organização do trabalho em grupo também é acompanhada pela CF e pelo Sindicato, garantindo-se a análise da ocupação dos postos de trabalho, ou a transferência do ocupante de posto afetado, assegurando-se a sua 'realocação' mediante treinamento.

A constituição do TPM (Manutenção Produtiva Total) também foi negociada. A realização de determinado conjunto de tarefas no trabalho em grupo, com vistas à melhoria da qualidade, da produtividade, da qualificação profissional e da qualidade de vida no trabalho, foi estabelecida num outro acordo coletivo em 1999, construído após dois anos de negociação e, talvez, o mais abrangente e complexo do tipo no Brasil. 
Um dos alvos prioritários dos acordos sobre a estrutura de cargos e salários foi a redução das disparidades. Os trabalhadores obtiveram uma nova estrutura com menor número de funções diferenciadas e maior número de salários dentro de um mesmo nível. Quando os trabalhadores passaram da gestão clássica com funções bem definidas, para a gestão participativa com trabalho em grupo, houve um aumento de $10 \%$ nos salários. Segundo o responsável pelo planejamento salarial, entrevistado, hoje se procura dar nomes mais genéricos às funções para que se possam ampliar os cargos com o conceito de "polivalência", vinculado às habilidades e competências. Os salários praticados pela empresa são compostos por um salário fixo e gratificações determinadas por um sistema de avaliação onde são contabilizados os retrabalhos, perdas e produtividade de cada um.

Segundo os trabalhadores entrevistados, a introdução das inovações organizacionais levou a uma intensificação do trabalho por vários motivos, entre os quais: redução do caminho percorrido pelas peças no 'chão-de-fábrica', com a reorganização do lay-out; redução da quebra de equipamentos e do tempo de máquinas paradas; e melhores condições ergonômicas de trabalho. Como resultado houve um aumento na produtividade de cerca de $20 \%$, que também foi favorecido pela redução de problemas relacionados ao absenteísmo e ao atraso de funcionários no trabalho. Uma pesquisa da empresa realizada com os funcionários, através de questionários para avaliar a satisfação em relação ao trabalho em grupo, obteve $91,3 \%$ de aceitação.

Dentre as dificuldades sociais enfrentadas pela empresa para implantar o trabalho em grupo podemos citar a baixa escolaridade dos funcionários, já que cerca de 30\% do pessoal não possui o primário completo. Esse problema dificultou a introdução de algumas ferramentas na produção como o CEP (Controle Estatístico do Processo), pois os funcionários não sabiam preencher planilhas, interpretar gráfico etc. Os integrantes dos grupos passaram a questionar as novas tarefas. Houve resistência nas gerências de produção e manutenção com a descentralização do poder, causada pela redução dos níveis hierárquicos - pelo menos $50 \%$ dos gerentes de 'chão-de-fábrica' foram demitidos pela Diretoria com a implantação dos grupos.

\subsection{O Caso da Mercedes-Benz de Juiz de Fora}

A fundação da fábrica da Mercedes Benz em Juiz de Fora - MG foi em setembro de 1997, sendo que o início das atividades ocorreu em 1999. Em 2005, a fábrica empregava 1093 trabalhadores diretos. A fábrica tem capacidade para produção de 70 mil veículos/ano e inicialmente produzia o veículo Classe A. Entretanto, em 2001, ela começou a produzir o veículo Classe C para exportação, para melhor aproveitamento de sua capacidade produtiva, em função da pouca aceitação do Classe A no mercado brasileiro. Em 2005, a produção total da fábrica foi de 3500 veículos, número muito abaixo da sua capacidade produtiva.

A planta está situada numa região com pouca tradição sindical, se comparada com a região do $\mathrm{ABC}$ paulista, seguindo uma tendência que pode ser observada em outras montadoras da nova migração.

A organização do trabalho na Mercedes-Benz Juiz de Fora está voltada para assegurar a flexibilidade do processo. Para isso, há uma ênfase na utilização da multifuncionalidade e da rotação de tarefas, por meio da adoção do trabalho em grupo.

A produção é totalmente organizada em células de 6 a 12 participantes, de acordo com as características de cada linha. As equipes de trabalho se reúnem duas vezes por semana, no horário de trabalho, por 30 minutos. Os grupos têm autonomia para planejar as férias, discutir as demissões, deliberar sobre as necessidades de qualificação e treinamento dos membros da equipe, decidir sobre o arranjo e a disposição do local de trabalho, a divisão do trabalho e a rotatividade de tarefas entre os participantes da equipe. Nas reuniões são discutidos os problemas técnicos, organizacionais e pessoais que dependem do grupo para serem solucionados, além da difusão de informações pertinentes ao trabalho.

De acordo com os entrevistados, os funcionários da equipe também têm autonomia para parar a linha caso ocorra algum problema. No entanto, quando perguntados se isso já ocorreu alguma vez, eles afirmam que não. Eles são responsáveis pela resolução do problema e, se não conseguirem solucioná-lo, o líder da área é acionado. 
Em relação à fábrica de São Bernardo, a Mercedes-Benz de Juiz de Fora apresenta mudanças tanto na estrutura hierárquica que é mais enxuta, contendo um número reduzido de níveis, quanto no número de cargos que foi significativamente reduzido.

O sistema de avaliação de desempenho da fábrica foge do modelo tradicional, utilizando a análise por competências e habilidades. Esse modelo foi desenvolvido, tomando-se por base as especificidades da planta de Juiz de Fora, segundo uma cultura local. A avaliação ocorre uma vez por ano e é utilizada para promoção de funcionários e para a definição de salários.

As políticas salariais das plantas de Juiz de Fora e São Bernardo não estão atreladas. O salário médio de um operador de Juiz de Fora é similar ao da região, sendo até 50\% menor que o de São Bernardo. Segundo o assessor de RH, a composição remuneratória inclui a remuneração fixa e a remuneração variável (incluindo a PLR).

Com relação à política salarial da empresa, uma reclamação constante dos trabalhadores entrevistados diz respeito à falta de critérios explícitos para definir a progressão das faixas salariais. Os trabalhadores fazem uma crítica indireta ao modelo de avaliação de desempenho, ao qual a remuneração está atrelada, por não entenderem os critérios de aplicação da avaliação. Para o nível operacional, a avaliação em $360^{\circ}$ é fechada em conjunto pelo funcionário e o líder, e é referendada pelo supervisor. Contudo, muitas vezes o funcionário se sente pressionado a acatar a avaliação do líder, sem ter espaço para questionamentos da avaliação. Para os operadores, esse sistema de avaliação torna o processo muito personalizado, e faz com que ocorram distorções nas avaliações e no privilégio dos funcionários que estão mais próximos dos líderes. Eles também consideram a política salarial injusta porque ela permite que operadores que têm a mesma função recebam salários distintos.

O Sindicato, por sua vez, esteve atento a essas reivindicações dos trabalhadores e se organizou para levar essa discussão para a direção do grupo na Alemanha, embasados pelos Princípios de Responsabilidade Social Daimler Chrysler, disponível na Intranet da empresa. Segundo esses princípios: "Dentro do âmbito da legislação nacional, a Daimler Chrysler respeita o princípio de pagamento igual por trabalho igual de igual valor, por exemplo, para homens e mulheres" (grifo da própria empresa, Daimler Chrysler, 2003).

Os dirigentes sindicais também observaram que ocorre uma diferenciação salarial significativa entre homens e mulheres, posto que os primeiros, em geral, têm uma média salarial maior do que as mulheres, ainda que ocupando os mesmos cargos.

O relacionamento da empresa com os trabalhadores é considerado por esses ( e também pelo Sindicato) como muito bom. Em todos os operadores entrevistados é possível perceber certo orgulho em fazer parte da MBB. Por outro lado, isso também é refletido na preocupação em manter o padrão de qualidade como uma moeda de troca com o grupo Daimler Chrysler para manutenção da planta; mesmo essa, operando muito abaixo de sua capacidade produtiva. Sobretudo no nível operacional, percebe-se que há uma solidariedade e um comprometimento maior em função da instabilidade da fábrica. A planta não tem Comissão de Fábrica reconhecida: existe uma comissão de representação de trabalhadores que funciona como representante dos trabalhadores junto à direção da planta, porém sem as garantias asseguradas às comissões.

Também o Sindicato afirma manter um ótimo relacionamento com a direção da empresa. Aproximadamente $18 \%$ do efetivo da empresa é sindicalizado, e a MBB-JF é uma das maiores e mais importantes empresas que compõem a base, junto com a Belgo Mineira.

O Sindicato dos Metalúrgicos de Juiz de Fora é filiado à Central Única dos Trabalhadores (CUT) e mantém intercâmbio constante com o Sindicato do ABC e também com a Comissão de Fábrica da Mercedes Benz de São Bernardo do Campo. Nessa troca, os dirigentes sindicais obtêm capacitação para as negociações com a empresa e tornam o movimento em Juiz de Fora mais fortalecido, pois as negociações na MBB-JF são acompanhadas e orientadas pelo Sindicato do $\mathrm{ABC}$ e pela própria Comissão. Além disso, o sindicato mantém também ligação com o IGMETALL, uma espécie de Confederação dos Metalúrgicos na Alemanha e com a Comissão de Fábrica da fábrica de Rastaad e outras do grupo Daimler Chrysler. Essa troca de experiências, que se traduz inclusive na ida de dirigentes do Sindicato de Juiz de Fora para acompanhar negociações e participar 
de seminários na Alemanha, permite a troca de experiências, orientação sobre temas como redução de jornada de trabalho, condições de trabalho, saúde e relacionamento com chefias e na negociação coletiva, e suporte em situações de paralisação. É interessante também destacar que a ação dos metalúrgicos do grupo Daimler Chrysler se dá em nível global, na medida em que há a possibilidade de deflagração de greves em qualquer planta do grupo, de maior ou menor relevância, em repúdio às ações praticadas pela empresa em qualquer de suas plantas no mundo.

\subsection{O Caso da Volkswagen de São Bernardo}

A fábrica da Volkswagen de São Bernardo foi inaugurada em 1959. Atualmente ela produz os modelos Gol, Fox Europa, Polo e Polo Sedan, Saveiro e Kombi. O número de funcionários diretos em 2005 era da ordem de 10 mil e 5 mil indiretos. Em 2000, o número de funcionários era de 19 mil. Nesse mesmo ano, a produção total da fábrica foi de aproximadamente 270 mil veículos e em 2005 foi de cerca de 380 mil (ANFAVEA, 2006).

O modelo adotado pela Volkswagen no processo de reestruturação produtiva foi o da produção enxuta, que consistiu num rigoroso downsizing, criando uma cadeia de fornecedores com uma estrutura piramidal.

Em meados de 1996, foi implantado o trabalho em grupo através das células de produção. Segundo a gerência, um dos objetivos do trabalho em células é tornar os trabalhadores polivalentes, incentivando a rotatividade de tarefas, sempre que necessário. Antes das células, a multifuncionalidade não era estimulada e os operadores se tornavam polivalentes por iniciativa própria ou pelas oportunidades. Entretanto, foi possível constatar que a rotação de tarefas somente ocorre em caso de ausência de algum membro; os operários não podem mudar de posto de trabalho sem autorização.

Outro objetivo da implantação das células é um maior controle da produção. Através da avaliação audit (índice de qualidade do produto feito no final da linha de montagem por amostragem) pode-se identificar o ponto da produção no qual estão ocorrendo falhas e, dessa forma, melhorá-lo com maior velocidade de ação. Esse controle também aumentou a responsabilidade de cada trabalhador, pois, como agora se sabe em qual célula o problema está ocorrendo, a cobrança é direta para que se melhore o desempenho. Além disso, o próprio grupo exerce pressão, uns sobre os outros, para que os indicadores estejam sempre em níveis de excelência.

A participação dos trabalhadores para melhorias na organização do trabalho pode vir por dois mecanismos: workshops e sugestões da própria célula. Os workshops são reuniões realizadas com engenheiros e técnicos para promover a melhoria contínua das células e não contam obrigatoriamente com a participação dos integrantes da célula. As sugestões das células surgem a partir de reuniões ocasionais onde o próprio trabalhador discute suas idéias dentro do grupo, e o monitor as leva aos superiores para análise. As reuniões das células não são periódicas, elas ocorrem quando é detectado algum problema. Essas reuniões substituem os antigos programas de sugestões, nos quais os funcionários recebiam prêmios por suas idéias; atualmente as sugestões não são remuneradas. A autonomia das células de trabalho é limitada aos aspectos operacionais e ainda está evoluindo.

Algumas dificuldades técnicas, gerenciais e sociais foram enfrentadas pela empresa na implantação do trabalho em grupo. As dificuldades técnicas estão relacionadas ao lay-out da produção e à presença de equipamentos anti-ergonômicos. Praticamente não houve nenhuma mudança significativa de lay-out para a adoção do trabalho em grupo, provocando o isolamento de alguns trabalhadores e causando dificuldades na comunicação entres os integrantes do grupo. Entre as dificuldades gerenciais está a falta de comprometimento de alguns membros da gerência, provocando a desmotivação dos funcionários. Alguns gerentes resistem em delegar responsabilidade aos grupos.

Outro tipo de dificuldade enfrentada com a implantação do trabalho em grupo relaciona-se, em grande parte, à baixa escolaridade da mão-de-obra de 'chão de fábrica', que gera problemas na rotação de alguns empregados em equipamentos modernos e flexíveis. Os trabalhadores com baixa escolaridade têm dificuldade em assumir as novas tarefas de gerenciamento do grupo nas funções relacionadas com a qualidade, logística e a administração dos integrantes da equipe. 
A remuneração dos trabalhadores de 'chão de fábrica', embora seja mais alta que a média na região, não se modificou com a implantação do trabalho em grupo e se mostrou incoerente com a estrutura de cargos e salários. Mesmo com o trabalhador passando a exercer novas funções no grupo, o salário permaneceu associado a categorias específicas e rígidas, e as promoções continuaram dependendo somente do tempo de serviço.

Apesar das dificuldades na implantação do trabalho em grupo apontadas acima, segundo dados fornecidos pela empresa, os resultados relacionados com o aumento da produtividade e da qualidade, diminuição do refugo e despesas gerais da célula, redução do número de acidentes e do absenteísmo foram todos positivos.

A planta da Volkswagen em São Bernardo reduziu, em 7,5 mil trabalhadores, a mão-de-obra empregada durante a década de 1990 (passando de 26,5 mil em 1990 para 19 mil em 2000 e 10 mil em 2005), em grande medida por causa da terceirização. É importante destacar que nesse mesmo período a fábrica terceirizou o sistema de bancos, a produção de partes elétricas e as peças e subconjuntos de componentes plásticos, a logística, a alimentação e a vigilância, entre outros. Segundo membros da Comissão de Fábrica da empresa, o salário médio pago nas empresas terceirizadas costuma ser $2 / 3$ do salário pago pela montadora. De acordo com o Secretário da Comissão de Fábrica (C.F.) da empresa:

Para o movimento sindical, até o momento, a terceirização tem sido, na maioria das vezes, causa de desemprego e 'precarização' das condições de trabalho. Concretamente, a terceirização na Volks tem conduzido à redução dos salários, à perda de benefícios sociais, à piora das condições de trabalho, à fragmentação da representação sindical, ao ataque às organizações e às conquistas sindicais.

Em contrapartida, observa-se que em paralelo, a empresa vem renovando a sua força de trabalho, contratando trabalhadores com um nível maior de escolaridade, além da exigência de um maior nível de formação dos trabalhadores terceirizados.

\section{$3.4 O$ caso da Volkswagen de Resende/RJ}

A fábrica de caminhões e ônibus da Volkswagen (VW) em Resende/RJ iniciou suas operações em 1996, sendo uma das primeiras plantas a serem construídas sob os auspícios do Novo Regime Automotivo, sendo também a primeira planta, no mundo, concebida dentro do novo conceito de produção denominado Consórcio Modular. Atualmente, a fábrica possui 3045 funcionários, desses, cerca de 500 apenas são da própria Volkswagen. A produção total da fábrica, em 2005, foi de aproximadamente 36 mil unidades (ANFAVEA, 2006).

A fábrica é formada por um consórcio de oito módulos (fornecedores), instalados na própria planta, cada um responsável por uma seqüência de montagem dos veículos, e a VW é responsável, na prática, pela verificação da qualidade dos produtos e pela coordenação das atividades dos outros sete módulos de montagem, além do projeto dos veículos e vendas.

No que tange aos recursos humanos que trabalham nos módulos, a gestão e a contratação dos funcionários dos módulos é realizada pelas próprias empresas fornecedoras. Contudo, esses trabalhadores têm os mesmos direitos e benefícios dos trabalhadores da VW; a média salarial é a mesma, e os percentuais de aumento de salários são iguais para todos.

É interessante considerar aqui as observações realizadas por Salerno (1998, apud BRESCIANI, 2001) acerca das possibilidades de envolvimento ensejadas pelo Consórcio Modular. Esse autor questiona se a competência da VW de produzir caminhões será mantida, se a firma está apta para assegurar a qualidade VW dos veículos produzidos, mesmo estando fora do cotidiano da produção. Em outros termos, ele questiona se é possível para a empresa "combinar a inovação dos produtos, crescimento empresarial e o processo de acumulação sem uma âncora no processo produtivo" (SALERNO, 1998 apud BRESCIANI, 2001). E, indo além, como garantir a participação e o envolvimento de trabalhadores que não estão vinculados à VW e que têm média salarial abaixo dos outros trabalhadores do setor no país, como ocorre na fábrica de Resende? 
Como destaca Rocha (2003), na contratação de trabalhadores para os módulos são valorizadas as competências "não formalizadas" (ou que não são adquiridas na escola ou na formação técnica) para o trabalho, além do requisito de formação. Essas competências não formalizadas são essenciais para a adaptação do trabalhador em um sistema de produção que por suas próprias características demanda trabalhadores polivalentes (são montados 30 modelos distintos, entre caminhões e ônibus, na mesma linha) e com um envolvimento e comprometimento maior na produção e, sobretudo, com a qualidade, uma vez que eles produzem um produto de outra empresa que não, aquela à qual estão vinculados.

O envolvimento dos trabalhadores na planta se dá, ainda, de forma muito restrita e em espaços delimitados pela própria gerência, e nesse sentido, como apontam diversos autores, a planta de Resende segue um modelo de organização do trabalho em equipes, conservador, sem maiores ganhos de autonomia e participação para os trabalhadores (ARBIX \& ZILBOVICIUS, 1997, BRESCIANI, 2001; ROCHA, 2003). Da mesma forma, como ressaltaram tanto os membros da Comissão de Fábrica quanto o representante sindical entrevistados, em nenhum momento os trabalhadores são consultados ou participam das discussões sobre inovações, ou sobre a introdução de novos modelos na linha. Essa característica da organização do trabalho também foi identificada por Arbix e Zilbovicius (1997) e Rocha (2003) em suas análises: "na visão deles (da VW), toda a concepção da planta reside em um sistema baseado no fluxo convencional da produção, que não dá espaço para o envolvimento do trabalhador ou do sindicato em sua configuração ou funcionamento" (ROCHA, 2003:21).

Além da exigência da polivalência para a execução das atividades cotidianas do posto de trabalho, existe um grupo de funcionários que são denominados como "multifuncionais", que conhecem e sabem executar todas as atividades presentes em seu módulo específico. Eles são responsáveis por corrigir eventuais defeitos que são descobertos na verificação de qualidade e por isso têm um salário maior do que os outros operadores do módulo.

Uma importante ferramenta utilizada para estimular a participação dos funcionários é a "caixa de sugestão" que recolhe propostas individuais dos trabalhadores. Outra ferramenta de participação, porém menos utilizada, são as reuniões denominadas "Bom Dia" nas quais são discutidos aspectos relacionados à qualidade, limpeza, segurança, além de constituir um espaço onde as orientações sobre metas de qualidade e produtividade são informadas aos funcionários.

Não obstante, como assinala Rocha (2003), ambas as instâncias de participação dos funcionários restringem o entrosamento e a autonomia, uma vez que a participação, nas caixas de sugestões, é individual, não favorecendo a reflexão em grupo, sobre o conteúdo das atividades, e as reuniões "Bom Dia" são mediadas pela gerência, que determina os pontos a serem discutidos e compartilhados pelo grupo.

Verifica-se, na linha de produção, nos módulos, um achatamento das estruturas hierárquicas, aproximando operadores e gerentes e facilitando a comunicação entre esses níveis. Um aspecto favorável a essa aproximação está na localização dos escritórios nos módulos, que ficam na própria linha de produção.

A empresa possui uma Comissão de Fábrica (CF). Segundo o relato de seus membros, muitas vezes, o sindicato se sente ameaçado pela sua atuação, não dando respaldo e nem possibilitando meios para a formação e informação da CF acerca das questões da fábrica. Em contraponto, para o dirigente sindical entrevistado, a relação com a CF é de apoio e cooperação; ela é vista como um braço do sindicato dentro da fábrica. Essa contradição entre a percepção da CF e do sindicato sobre suas relações se explica pela diferença existente entre a atuação do dirigente sindical responsável pela VW, entrevistado para esse estudo, e a posição ideológica do sindicato como um todo. Por não encontrar respaldo político-ideológico para a sua ação no Sindicato dos Metalúrgicos de Volta Redonda, a CF da VW busca freqüentemente as orientações do Sindicato dos Metalúrgicos do $\mathrm{ABC}$, principalmente a seção de São Bernardo, onde se localiza a maior planta da VW no país, além de recorrer à Federação Mundial das Comissões de Fábrica da VW, na Alemanha.

Contrariamente ao discurso da CF, o trabalho de Ramalho e Santana (2002) aponta para um avanço nas conquistas do sindicato, no que diz respeito à negociação salarial e à representação operária, principalmente se considerar o pouco tempo de experiência do sindicato nas negociações desse setor. 
Embora seja, desde o início (no caso da VW), considerado um sindicato mais dócil (por ser ligado a uma central sindical mais conservadora como a Força Sindical), a atuação sindical tem sido bastante ativa, com um grau de combatividade que garante uma mobilização permanente dos operários da fábrica. Os resultados conseguidos nas negociações salariais mostram um sindicato que vem rapidamente se adequando às necessidades dos trabalhadores nesse setor. Isso comprova a possibilidade de incorporação quase imediata de pautas de reivindicação que vêm sendo discutidas em sindicatos com mais experiência no setor. (RAMALHO \& SANTANA, 2002:101)

É importante assinalar que, segundo relatos dos trabalhadores e do diretor sindical entrevistado, um dos fatores que influenciaram a escolha do município de Resende para a construção da fábrica pela VW foi a existência de um sindicato que, apesar de ser um dos mais tradicionais do setor, por conta de uma história de combatividade com a Companhia Siderúrgica Nacional, não tinha nenhuma experiência no setor automotivo e não tinha nenhuma base formada no município de Resende. Além disso, também pesou, para a montadora, o fato de o sindicato ser vinculado à Força Sindical, considerada mais aberta ao diálogo e à negociação do que à CUT. Segundo relato de um dirigente do sindicato, os representantes da empresa afirmaram categoricamente estarem procurando um local onde não tivessem grandes problemas com o sindicato, ao contrário do $\mathrm{ABC}$, e que pudessem ter o sindicato como um "parceiro".

É importante assinalar que a promessa de "parceria", obtida junto ao Sindicato, constitui uma moeda de troca para a geração de um número determinado de postos de trabalho, fixado no acordo firmado entre a empresa e o governo quando da implantação da fábrica. Entretanto, o número de empregos efetivamente gerado ficou muito abaixo do que foi prometido pela empresa, conforme apontam (RAMALHO \& SANTANA, 2002).

\section{Conclusões}

A partir da análise dos elementos das relações salariais nos estudos de caso é possível estabelecer vários níveis de comparação, não apenas entre plantas de montadoras diferentes, mas também entre as plantas de uma mesma montadora, localizadas em regiões distintas.

No que tange à organização do trabalho, todas as plantas estudadas, tanto as que foram reestruturadas quanto as mais novas, adotam o trabalho em grupo, com algumas diferenças entre elas. O trabalho em grupo, nas plantas da Mercedes Benz, parece ter maior autonomia do que nas, da Volkswagen; além disso, as discussões nos grupos abrangem desde problemas técnicos até problemas pessoais, conforme visto nos relatos dos casos. Percebe-se, ainda, que houve uma preocupação, na Mercedes Benz de São Bernardo, de preparar a fábrica para a adoção do trabalho em grupo, implementando até mesmo mudanças de lay out para obter maior aproximação dos trabalhadores na linha. O processo de mudança organizacional também foi negociado com os trabalhadores, por meio do sindicato, num acordo inédito no setor. Tal como apontado pelos entrevistados, a Mercedes procurou aproximar o tipo de trabalho em grupo, utilizado, do modelo 'sociotécnico' de Kalmar, que propõe maior autonomia das funções dos grupos e participação dos funcionários. Comparando com o caso da Volkswagen de São Bernardo, na Mercedes-Benz, os grupos de trabalho têm maior autonomia na gestão da produção, no referente a: divisão do trabalho, interrupção da produção, rejeição de matéria-prima não conforme, responsabilização pelas manutenções primarias e operação polivalente das máquinas.

Nas plantas da Volkswagen, o trabalho em grupo utilizado está mais próximo daquele proposto pela lean production, que prevê a participação dos funcionários, limitada apenas aos aspectos técnicos e operacionais da produção. A implantação do trabalho em grupo, em São Bernardo não foi acompanhada por uma mudança do lay out, assim como não houve um treinamento dos trabalhadores no novo sistema de produção, o que dificultou a integração de trabalhadores menos qualificados no trabalho em grupo e sua rotação nas diferentes funções. Na planta de Resende, o trabalho em grupo possui características semelhantes: não há regularidade nas reuniões dos grupos, os trabalhadores não são consultados quando ocorrem mudanças no processo e a autonomia e a participação são muito restritas, seguindo um modelo de trabalho em grupo, considerado conservador por vários autores, tal como foi relatado no estudo de caso. 
As características que envolvem a adoção do trabalho em grupo, em cada planta são também encontradas nas relações de hierarquia. Na Mercedes Benz de São Bernardo, o trabalho em grupo foi acompanhado de uma diminuição dos níveis hierárquicos e de uma descentralização da tomada de decisão e de administração dos processos, com a preparação dos trabalhadores para assumir as novas funções. Na planta de Juiz de Fora, a hierarquia é ainda mais achatada do que na primeira, possibilitando uma integração maior entre os diferentes níveis.

Na Volkswagen de São Bernardo, a implantação dos grupos de trabalho enfrentou a resistência dos gerentes que não querem delegar responsabilidades, além de demonstrarem não estar comprometidos com os objetivos do trabalho em grupo, gerando conseqüentemente falta de motivação nos funcionários. Na planta de Resende, essas relações são ainda mais complexas, pois há uma hierarquia entre os módulos e a própria Volkswagen. É necessário destacar que os trabalhadores da linha não são da Volkswagen, o que dificulta o envolvimento desses com os objetivos da empresa.

Quanto ao sistema de remuneração, é interessante notar que, quando da introdução do trabalho em grupo na Mercedes Benz, os trabalhadores tiveram um aumento salarial de $10 \%$. Na Volkswagen São Bernardo, em contraposição, foi apontada uma incoerência entre as novas funções criadas pelo trabalho em grupo e a estrutura de cargos e salários, correspondente ao sistema de organização do trabalho anterior, associada a categorias e com promoções apenas por tempo de serviço. Nas plantas mais novas verificou-se, em Juiz de Fora, a adoção do sistema de avaliação por competências, que é alvo de críticas dos funcionários por não possuir critérios claros de avaliação e promoção. Cabe ressaltar que os salários pagos pela montadora em Juiz de Fora são até 50\% menores do que em São Bernardo. O mesmo ocorre na planta da Volkswagen Resende, que buscou uma região para construção da fábrica que tivesse uma média salarial baixa em relação ao $\mathrm{ABC}$ paulista e um sindicato com pouca tradição de negociação na indústria automobilística.

No que diz respeito à atuação dos sindicatos, deve-se considerar o histórico de enfraquecimento do movimento sindical como um todo nos últimos vinte anos, em função de sucessivas crises econômicas e a profunda transformação do parque industrial brasileiro, em decorrência do processo de globalização. Tal enfraquecimento teve como conseqüência a precariedade das relações de trabalho e a diminuição do salário médio dos trabalhadores, sobretudo em regiões pouco industrializadas. Nesse contexto de crise do emprego e dos salários (salvo em regiões com conquistas salariais já garantidas e sindicatos mais fortes como o $\mathrm{ABC}$ paulista), a atuação dos sindicatos fica, na maioria das vezes, restrita às negociações para impedir o enxugamento de empresas e o aumento de demissões. Adicionado a isso, os acordos ficam submetidos à barganha por postos de trabalho, ainda que por baixos salários. Esse fato é evidenciado nas escolhas para construção de novas plantas nos greenfields, possibilitando condições ótimas de barganha para as empresas junto aos trabalhadores e aos sindicatos.

Vale destacar que, nesse cenário de enfraquecimento dos sindicatos, são fundamentais as ações de cooperação entre sindicatos mais fortes e os mais enfraquecidos, como ocorrem entre os sindicatos de São Bernardo e Juiz de Fora e do primeiro com a Comissão de Fábrica da Volkswagen. Essas ações de cooperação são uma forma de assegurar não apenas uma globalização das estratégias de gestão da força de trabalho das empresas, mas também das formas de defesa e proteção ao trabalho.

$\mathrm{Na}$ análise dos casos à luz da estrutura analítica de Durand, conclui-se que o estudo da imbricação dos elementos das relações salariais destaca os conflitos existentes não apenas entre a dinâmica dos modelos produtivos e dos conflitos oriundos de cada contexto específico, em cada região. Ele, também, nos permite identificar as diferenças nas formas de gestão do trabalho em cada região por uma mesma montadora, embora ela mantenha suas características mais gerais. Até onde se pode perceber, todas as fábricas estudadas utilizaram adaptações do trabalho em grupo, seja do Modelo Japonês (como na Volkswagen), seja do Modelo Kalmariano (como na Mercedes Benz), sendo que essas adaptações variam de região para região.

Deve-se ressaltar que, hoje, a obtenção de acumulação de capital se dá à custa da precariedade das relações de trabalho, do enfraquecimento dos sindicatos, conforme apontado anteriormente, e da flexibilidade do trabalho e das condições de trabalho e produção (na qual se inclui a 'externalização' da produção para países periféricos e semi-periféricos). Tais características denotam o caráter desigual da relação entre capital e trabalho atualmente, 
a qual, se analisada sob o enfoque da coerência proposto por Durand, demonstra que as condições de trabalho, obtidas pelos elementos da relação salarial no modelo 'fordista' eram mais favoráveis aos trabalhadores do que aquelas impostas pelo contexto atual. Como exemplo, pode-se citar o elevado aumento no número de unidades produzidas em ambas as montadoras, no período 2000-2005, aliado à redução drástica do número de trabalhadores e à terceirização, no caso da Volkswagen.

Ressalta-se, ainda, a importância da estrutura de relações salariais como ferramenta de análise, por oferecer uma abordagem dinâmica que aponta as contradições e a evolução dos modelos produtivos em suas adaptações na realidade. 


\section{Referências}

ANFAVEA. Anuário Estatístico. São Paulo. Disponivel em< http://www.anfavea.com.br.> 2006

ARBIX G. \& ZILBOVICIUS M. O Consórcio Modular da VW: um novo modelo de produção? In: --- (orgs.). A Invenção dos Carros. São Paulo: Ed. Scritta, 1997

BRESCIANI, L.P. Flexibilidade e Reestruturação: o trabalho na encruzilhada. In: São Paulo em Perspectiva. São Paulo: Fundação SEADE, vol. 1, n¹1. 1997

, Labour and Innovation in the Brazilian Truck Industry: The Case of MBB São Bernardo and VW-C Resende. In: Actes du GERPISA, n.30. França. Disponivel em <www.gerpisa.univ-evry.fr.> 2001

CARLEIAL, L.; GOMES FILHA, M.L.F. \& NEVES, L.S. Modèles Industriels et quelques elements de la relation salariale dans les firmes reseaux commandees par les constructeurs automobiles dans la region metropolitaine de Curitiba-Paraná (Brésil): Les cas de Volks-Audi et de Renault, In: Dixieme Rencontre Internationale du GERPISA, Juin, Paris, France. 2002

CICOUREL, A Teoria e método em pesquisa de campo. In: ZALUAR, A. (org.) Desvendando Máscaras Sociais. Rio de Janeiro: Ed. Francisco Alves, 1990

DAIMLER-CHRYSLER. Princípios de Responsabilidade Social. Documento Interno, Juiz de Fora, 2003

DURAND, J.P. Introduction. Les Modèles de la Relation Salariale. In: DURAND, J.P., STEWART, P. \& CASTILLO, J.J., L'avenir du Travail à la Chaîne. Paris: Édition La Decouverte, 1998

; STEWART, P. \& CASTILLO, J.J. Conclusions. In: DURAND, J.P.; STEWART, P. \& CASTILLO, J.J., L'avenir du Travail à la Chaîne. Paris: Édition La Decouverte, 1998

RAMALHO, J. R. \& SANTANA, M.A. A Indústria Automobilistica no Rio de Janeiro: relações de trabalho em um contexto de desenvolvimento regional. In: NABUCO, M.R.; NEVES, M. de A. \& NETO, A.M. de C., Indústria Automotiva: a nova geografia do setor produtivo. Rio de Janeiro: DP\&A Editora, 2002

ROCHA, L. de M. O Novo Discurso da Qualificação Profissional e os Trabalhadores do 'Consórcio Modular' em Resende/RJ". In: Trabalhadores, Sindicatos e a nova Questão Social. Seminário Intermediário. GT ANPOCS, Universidade de São Paulo, São Paulo. Disponível em <http://www.sindicalismo.bridge.com.br.> 2003

Womack, J.P.; Jones, D.T. \& Roos, D. A Máquina que Mudou o Mundo. Rio de Janeiro: Ed. Campus, 1992 